\title{
Pascal Pia, Au temps du disque vert, Lettres à Franz Hellens (1922-1934)
}

\section{Fabio Scotto}

\section{Q OpenEdition \\ 1 Journals}

\section{Edizione digitale}

URL: http://journals.openedition.org/studifrancesi/9329

DOI: $10.4000 /$ studifrancesi.9329

ISSN: 2421-5856

\section{Editore}

Rosenberg \& Sellier

\section{Edizione cartacea}

Data di pubblicazione: 1 juin 2008

Paginazione: 221-222

ISSN: 0039-2944

\section{Notizia bibliografica digitale}

Fabio Scotto, «Pascal Pia, Au temps du disque vert, Lettres à Franz Hellens (1922-1934)», Studi Francesi

[Online], 154 (LII | I) | 2008, online dal 30 novembre 2015, consultato il 11 janvier 2021. URL: http:// journals.openedition.org/studifrancesi/9329; DOI: https://doi.org/10.4000/studifrancesi.9329

Questo documento è stato generato automaticamente il 11 janvier 2021.

\section{(c) (i) (9)}

Studi Francesi è distribuita con Licenza Creative Commons Attribuzione - Non commerciale - Non opere derivate 4.0 Internazionale. 


\title{
Pascal Pia, Au temps du disque vert, Lettres à Franz Hellens (1922-1934)
}

\author{
Fabio Scotto
}

\section{NOTIZIA}

PASCAL PIA, Au temps du disque vert, Lettres à Franz Hellens (1922-1934), textes réunis et présentés par René FAYT, Caen, Imec éditeur, 2006 («Pièces d’Archives»), pp. 110.

Dobbiamo a René Fayt, conservatore onorario della Riserva delle Biblioteche dell'Université libre di Bruxelles, questo volume che raccoglie le lettere di Pascal Pia (1903-1979) al romanziere e grande animatore di riviste Franz Hellens (1881-1972). Il libro comprende un' «Introduction» (pp. 7-13), che ben ripercorre le fasi salienti della creazione della rivista «Le Disque vert», fondata nel 1921 (la co-diresse nel 1925 Henri Michaux), la sua fusione con «La lanterne sourde», che dà vita agli «Écrits du nord» (1922-1923), poi il ritorno alla denominazione originaria del periodico, di qui in poi costantemente mantenuta, pur se parallela all'esperienza hellensiana d'altre testate, fino al 1957. Due brevi profili di Pia e Hellens ne tratteggiano la personalità e l'opera (pp. 14-18), rivelandone la capacità di coagulare attorno a loro, grazie alle riviste, alcune fra le figure letterarie più autorevoli del loro tempo, come si può evincere dal «Tableau chronologique des revues publiées par Franz Hellens» (pp. 19-22). Se uno dei limiti dell'opera appare quello di proporre un epistolario a una sola voce, quella di Pia, essendo assenti le missive del suo corrispondente Hellens, tuttavia esso risulta di particolare interesse per quanto sa testimoniare della fitta rete di rapporti letterari che il giovane Pia si dimostra capace d'intessere, spesso offrendoli alla rivista dell'amico belga, cui lo lega un rapporto di devota fedeltà e ammirazione più forte di ogni disparità di vedute (pp. 62-63) e tale da indurlo a preoccuparsi anche dei risvolti pratici, quali la ricerca di un tipografo, di un libraio distributore e via dicendo. La fitta e puntuale annotazione a piè di pagina di Fayt ha il merito non soltanto di supplire, per così dire, all'assenza di Hellens, con dovizia di dettagli filologici e storici e una ricca documentazione bibliografica sui personaggi evocati, ma anche di contribuire a 
illuminare alcuni spunti nodali delle lettere, quali, ad esempio, la polemica antiunanimistica (Lettre IX, pp. 45-49) - che prescinde dal riconoscimento del talento pur riconosciuto a Romains - quella contro il simbolismo (Lettre XII, pp. 55-56), ritenuto morto, e quella, violentissima, contro i surrealisti, che Pia non esita a mandare a quel paese («Mais comme ces MM. prennent des airs menaçants il est tout de même bon qu'on les envoie se faire foutre», p. 79). In appendice alcuni documenti autentici, l'«Index des auteurs cités» (pp. 103-106) e l'«Index des titres cités» (pp. 107-109). 